\title{
Effects of the durations of conditioned stimulus and non-CS period on conditioned suppression in the rat
}

\author{
KIYOSHI ISHII ${ }^{1}$
}

Department of Psychology, Faculty of Letters, Nagoya University, Chikusa-ku, Nagoya 464-01

\begin{abstract}
Employing the conditioned suppression paradigm, this study aimed at to investigate how durations of conditioned stimulus (CS) and non-CS period ( $\overline{C S}$ ) affect the learning of stimulusstimulus relationship. Five groups of 10 rats in each were trained for the suppression of waterlicking to CS (tone) by pairing it with US (mild foot-shock) in the different combinations of $\mathrm{CS}$ and $\overline{\mathrm{CS}}$ duration. After 10-day conditioning sessions, rats were given four test trials in which 10-s CS was presented without US. The results of the test revealed that the subjects with a lower CS $/ \overline{C S}$ ratio acquired a greater degree of suppression to the CS, and that the suppression was found in a similar level among the groups given the same CS/ $\overline{C S}$ ratio in spite of the difference in absolute durations of the CS and $\overline{C S}$.
\end{abstract}

Key words: conditioned suppression, CS duration, rats, water-licking.

When hungry rats are initially trained to press a lever for getting food and then repeatedly exposed to light as a conditioned stimulus (CS) paired with brief electric shock as unconditioned stimulus (US), the lever-press responses come to be suppressed by the presentation of the light. This phenomenon has been well known by the term of " conditioned suppression". Many investigators have used this phenomenon to test the proposed models of animal learning, for this paradigm can control the stimulus presentation independently of subjects' behaviour and can also measure the strength of suppression during the CS presentations as an index of learning.

Davis and Wright (1979) pointed out wide ranges of variations of many parameters used in different experiments on conditioned suppression. Among these, the wide variation of CS duration can be seen. It has been shown that in conditioning experiments of fixed-time sessions, the rate of acquisition was affected by CS duration (e.g., Mahoney \& Ayres, 1976; Odling-Smee, 1975).

1 The author is very grateful to Dr. Keiichiro Tsuji for his comments on the manuscript.
However, it is also pointed out that duration of non-CS period affects the rate of learning (e.g., Rescorla \& Wagner, 1972). Obviously, in a fixed-time session, the variation in CS duration inevitably results in the variation of non-CS period. Then, even if an experiment with fixed time session shows that the levels of suppression are different among the groups differing in CS duration, it is impossible to conclude that CS duration per se is the cause of the difference.

The experiments by Gibbon, Baldock, Locurto, Gold, and Terrace (1977) showed that tie ratio of duration of CS period to that of non-CS period (CS/ $/ \overline{C S}$ ), not the duration of either, is the determinant of learning level. They trained several groups of pigeon in an auto-shaping paradigm, with different CS and session duration. The results of experiments showed that the same level of learning was obtained among groups with the same $\mathrm{CS} / \overline{\mathrm{CS}}$, and that the smaller this ratio, the more the subjects acquired the CS-US contingency.

The present experiment aimed to reexamine the findings reported by Gibbon et al. (1977) by the conditioned suppression paradigm in the rat. Water licking 
was considered more suitable for this purpose than lever-pressing, especially when the CS duration was brief.

\section{Method}

Animals. Subjects were fifty male rats of Wistar strain which were born and had been reared in the Animal Laboratory of the Psychology Department, Nagoya University. They were about 60 days of age at the start of the experiment and were housed individually throughout it.

Apparatus. Two experimental boxes (20 $\times 10 \times 15 \mathrm{~cm}$ ) were placed in a sound-attenuating room and used for licking training and conditioning. A hole was opened in the front wall of each box, $5 \mathrm{~cm}$ above the floor, and animals licked the nozzle of water-drinking tube through the hole. The front and rear walls were made of opaque plexiglass while the ceiling and the side walls were made of clear acrylic plastics. The floor of the box was made up of $3 \mathrm{~mm}$ stainless-steel rods spaced $10 \mathrm{~mm}$ apart and the rods were connected to a shock generator. A speaker was set $30 \mathrm{~cm}$ under the boxes and through it $2 \mathrm{kHz}$ tone of $75 \mathrm{db}$ was presented as CS. The house light set above the boxes gave a dim illumination of $.5 \mathrm{~lx}$ throughout the sessions. Each water licking was converted to an electric pulse by National-Electric touch sensor (NZ8340) and fed into a counter.

Procedure. For the first three days animals were habituated to the restricted water supply in their homecages. Training of water licking started on the fourth day and lasted for 14 days. Each animal was placed in the box and allowed to lick the water nozzle for six minutes in each session. The number of lickings in every 30 seconds was recorded.

The training was followed by the conditioning sessions which lasted for ten consecutive days. In each session the animal was given two paired presentations of tone and shock $(.5 \mathrm{~mA}, 1 \mathrm{~s})$. The shock was delivered to animal's feet through the floor grid, and its onset was synchronized to CS termination.

According to different combinations of the durations of the CS and session period, the animals were assigned to one of five groups of ten animals each. Groups were matched in the mean number of lickings in the last training session. In Group 160-10, each session was 160 s long and the duration of each CiS was $10 \mathrm{~s}$, while in Group 160-30 30-s CS was presented in the session of the same duration. Group 480-10 received 10-s CS in 480-s session, while Groups 480-30 and 480-90 were exposed to $30-$ and $90-\mathrm{s}$ CS, respectively. Thus the duration ratio of CS to non-CS (CS/CS) was $3 / 5$ for Group 160 30 (CS: $30 \times 2=60 \mathrm{~s}, \overline{\mathrm{CS}}: 160-60=100 \mathrm{~s}$; $60 / 100=3 / 5)$ and Group 480-90, 1/7 for Groups $160-10$ and $480-30$, and $1 / 23$ for Group 480-10.

For the groups with 160-s session duration, the temporal location of CS offset was at 70 seconds after the start of each session, while that of the second one was immediately before the end of the session. For the groups with 480-s session, the first CS offset was at the point of 210 seconds, while the second CS offset was immediately before the end of the session. The number of lickings was recorded every ten second.

Following the conditioning sessions, all animals were given four test trials. The procedure in each trial was as follows: After the subject performed initial 200 licks, the base-line recording of licking was made for a 10-s period. After this period, a 10-s CS was presented and the number of licks was measured during the presentation. The next trial began with another 200 licks, which was followed by 10-s baseline and CS periods.

Throughout the training and conditioning sessions, animals were allowed to drink water for 10 minutes in their homecages after they had completed each session. 
Table 1

Results of the test session

\begin{tabular}{cccccc}
\hline $\begin{array}{c}\text { Groups } \\
(\mathrm{CS} / \mathrm{CS})\end{array}$ & $\begin{array}{c}160-10 \\
(1 / 7)\end{array}$ & $\begin{array}{c}160-30 \\
(3 / 5)\end{array}$ & $\begin{array}{c}480-10 \\
(1 / 23)\end{array}$ & $\begin{array}{c}480-30 \\
(1 / 7)\end{array}$ & $\begin{array}{c}480-90 \\
(3 / 5)\end{array}$ \\
\hline latency to 200 lickings & $70.5 \mathrm{~s}$ & $65.5 \mathrm{~s}$ & $76.5 \mathrm{~s}$ & $81.7 \mathrm{~s}$ & $79.1 \mathrm{~s}$ \\
$\mathcal{N}$ of lickings in pre-CS $(A)$ & 52.3 & 51.7 & 54.4 & 58.8 & 48.2 \\
$\mathcal{N}$ of lickings in CS $(B)$ & 13.8 & 26.9 & 7.1 & 15.8 & 23.8 \\
suppression ratio $[B /(A+B)]$ & 0.21 & 0.34 & 0.12 & 0.21 & 0.33
\end{tabular}

Through the conditioning and testing sessions, the level of learning was measured by calculating a ratio of form $A$ / $(A+B)$, proposed by Kamin (1969). Here $A$ represents the rate of licking during CS and $B$ represents the rate of licking during equivalent period of time immediately preceding the CS. Thus a ratio of .5 signifies no differential suppression to the $\mathrm{CS}$, whereas a ratio of .0 signifies complete suppression.

\section{Results and Discussion}

The overall mean rate of lickings in the final training session was 5.3 licks per second and showed no significant differences among the groups. This rate was reduced to about three or four per second in the final conditioning session. The greater CS/CS ratio, the smaller the rate was. However, the differences were not significant among groups.

Figure 1 presents the mean suppression

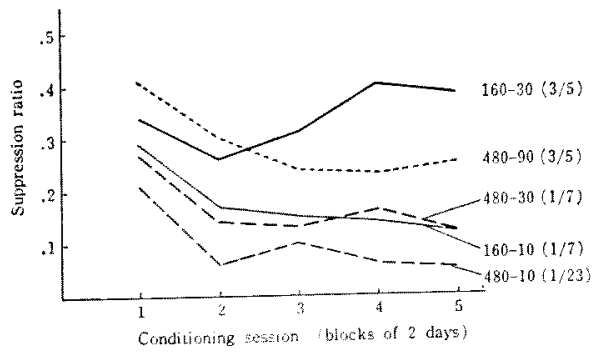

Fig. 1. Mean suppression ratio of each group as a function of conditioning sessions. The numbers in parentheses after group names indicate CS $/ \overline{C S}$ ratio. ratio for each group as a function of 2-day blocks of conditioning. For all but Group $160-30$, the suppression ratio decreased as the session proceeded, and the decreasing gradients became smaller which suggest that asymptotic levels of suppressions were reached at the end of the conditioning session. Also, the suppression was acquired more rapidly in the groups with smaller $\mathrm{CS} / \overline{\mathrm{CS}}$.

To ascertain that the different levels of conditioning shown in Fig. 1 were not caused by small amount of suppression in early part of CS presentations due to temporal conditioning in long-CS groups, each CS was segmented into three units and the suppression ratio was calculated for each unit. This was done only for the groups given 30 - or 90 -s CS. There were no differences among the units in any of these groups.

Table 1 shows the means of four indices for the five groups in the test session. Kruskal-Wallis analysis of variance of these indices revealed that significant overall group difference was seen only in the number of lickings in CS period $(H=$ $13.43, p<.01)$ and in SR $(H=14.66, p<$ $.01)$. Subsequent Mann-Whitney tests for these two indices revealed that: (a) Group 480-10 (1/23) was suppressed more than the other four groups. (b) Groups 480-30 (1/7) and 160-10 (1/7) did not differ from each other, but the two groups differed from Groups 160-30 (3/5) and 480-90 (3/5). (c) Groups 160-30 (3/5) and 480-90 (3/5) did not differ from each other.

The test clearly showed that CS/ $\overline{\mathrm{CS}}$, but 
not the absolute duration of either variable, determined the amount of conditioned suppression, and that the level of suppression was inversely related to the ratio. It is important to note that groups did not differ in the baseline level of licking as shown in the second row of Table 1. The results of this study as a whole reconfirmed the findings obtained by Gibbon et al. (1977).

A possible approach to explain these results is to assume that animals discretize conditioning session into trial unit of CS and non-CS. Several models have been proposed based on this view (for examples, Gibbon \& Balsam, 1981; Gibbon, Berryman, \& Thompson, 1974). They predict that the smaller CS/CS would produce the higher level of acquisition if the duration of CS is kept constant. However, these models could not explain why equal level of suppression is attained by the groups of the same CS/CS ratio with different CS durations.

\section{References}

Davis, H., \& Wright, J. 1979 Procedural and parametric variability in studies of conditioned suppression. Bulletin of Psychanomic Society, 14, 149-150.

Gibbon, J., Baldock, M. D., Locurto, L., Gold, L.,
\& Terrace, H.S. 1977 Trial and intertrial durations in autoshaping. Journal of Experimental Psychology: Animal Behavior Processes, 3, 264-284.

Gibbon, J., \& Balsam, P.D. 1981 Spreading association in time. In C.M. Locurto, H.S. Terrace \& J. Gibbon (Eds.), Autoshaping and conditioning theory. New York: Academic Press. Pp. 219-253.

Gibbon, J., Berryman, R., \& Thompson, R. L. 1974 Contingency spaces and measures in classical and instrumental conditioning. Journal of the Experimental Analysis of Behavior, 49, 732-764.

Kamin, L.J. 1969 Predictability, surprise, attention and conditioning. In B. Campbell \& R. Church (Eds.), Punishment and aversive behavior. New York: Appleton-Century-Crofts. Pp. 279-296.

Mahoney, W. J., \& Ayres, J.J.B. 1976 One-trial simultaneous and backward fear conditioning as reflected in conditioned suppression of licking in rats. Animal Learning and Behavior, 4, 357362.

Odling-Smee, F.J. 1975 Background stimuli and the inter-stimulus interval during Pavlovian conditioning. Quarterly Journal of Experimental Psychology, 27, 387-392.

Rescorla, R. A., \& Wagner, A. R. 1972 A theory of Pavlovian conditioning: Variations in the effectiveness of reinforcement and nonreinforcement. In A.H. Black \& W. Prokasy (Eds.), Classical condiitoning II. New York: Appleton-Century-Crofts. Pp. 64-99.

(Received May 31, 1988; accepted Sept. 9, 1989) 